\title{
Medical Interruption of Pregnancy in the Second Trimester at the Principal Clinic of the Togolese Association of Family Well-Being Planning Center (ATBEF): About 25 Cases
}

\author{
Bingo Kignomon M'bortche1 ${ }^{*}$, Baguilane Douaguibe ${ }^{2}$, Kossi Edem Logbo-Akey3, \\ Dédé Regina Ajavon ${ }^{3}$, Tina Ayoko Ketevi' ${ }^{2}$, Akila Bassowa ${ }^{4}$, Francis Baramna-Bagou ${ }^{1}$, \\ Koffivi Toovi-Madjé1, Abdoul-Samadou Aboubakari³ ${ }^{3}$ Koffi Akpadza² \\ ${ }^{1}$ Principal Clinic of the Togolese Association of Family Well-Being Planning Center (ATBEF), Lomé, Togo \\ ${ }^{2}$ Department of Gynecology-Obstetrics of the CHU Sylvanus Olympio, Lomé, Togo \\ ${ }^{3}$ Department of Gynecology-Obstetrics of the CHU Kara, Kara, Togo \\ ${ }^{4}$ Department of Gynecology-Obstetrics of the CHU Campus, Lomé, Togo \\ Email: *mbortche@yahoo.fr
}

How to cite this paper: M'bortche, B.K., Douaguibe, B., Logbo-Akey, K.E., Ajavon, D.R., Ketevi, T.A., Bassowa, A., Baramna-Bagou, F., Toovi-Madjé, K., Aboubakari, A.-S. and Akpadza, K. (2022) Medical Interruption of Pregnancy in the Second Trimester at the Principal Clinic of the Togolese Association of Family Well-Being Planning Center (ATBEF): About 25 Cases. Open Journal of Obstetrics and Gynecology, 12, 81-92.

https://doi.org/10.4236/ojog.2022.121008

Received: December 24, 2021

Accepted: January 23, 2022

Published: January 26, 2022

Copyright $\odot 2022$ by author(s) and Scientific Research Publishing Inc. This work is licensed under the Creative Commons Attribution International License (CC BY 4.0).

http://creativecommons.org/licenses/by/4.0/ (c) (i) Open Access

\begin{abstract}
Introduction: Medical termination of pregnancy is a therapy that considerably reduces the number of obstetrical complications that can lead to maternal death and the number of births of children with diseases or malformations that are incompatible with life. Objective: To study the practice of medical termination of pregnancy at the Principal Clinic of the Togolese Association of Family Well-Being Planning Center (ATBEF). Methodology: This was a retrospective and descriptive study conducted at the Principal Clinic of the Togolese Association of Family Well-Being Planning Center (ATBEF) covering the period from May 1st, 2012 to April 30th, 2021, i.e. a period of 9 years. All patients who underwent a medical termination of pregnancy during the study period and whose term of pregnancy was $<28$ weeks of amenorrhea were included in this study. Information was collected on a survey sheet from the patients' clinical records, admission and hospitalisation registers, referral forms and operative report registers. Data were entered and analyzed using Excel, World and epi-info 7.2.2. The main variables studied were hospital frequency, diagnostic means, main indications, means of evacuation and maternal prognosis. Result: 25 patients were identified and represented $0.5 \%$ of deliveries. Fetal, maternal and obstetric causes were the main indications for medical termination of pregnancy in respectively $28 \%, 20 \%$ and $52 \%$. Obstetrical ultrasound was performed in $100 \%$ of patients. These ultrasounds allowed us to determine fetal vitality and to find some fetal malformations
\end{abstract}


(28\%) and some anomalies in the fetal appendages (48\%). Clinical examination alone was used to diagnose $24 \%$ of indications. In $68 \%$ of cases, the clinical examination and ultrasound were used to establish the indication. The most commonly used evacuation technique was medication in $88 \%$ of cases. Caesarean section was chosen for urgent cases in $12 \%$. Uterine haemorrhage and post-abortion endometritis were the main complications. Conclusion: Medical termination of pregnancy is a delicate subject requiring multidisciplinary management. This series has allowed us to highlight our singularities, and will allow us to improve the management of our patients, in the prevention of haemorrhage and other complications.

\section{Keywords}

Medical Termination of Pregnancy, Indications, Technique, Togo

\section{Introduction}

Medical termination of pregnancy (MTP) is an induced abortion based on medical indications given by two independent experts in case of danger to the mother to continue the pregnancy or risk of giving birth to a child with a disease or malformation incompatible with life [1].

With the development of ultrasound and prenatal diagnostic techniques, the foetus has become a patient in its own right and the number of medical terminations of pregnancy is increasing [2]. Prenatal diagnosis in the first and second trimester is increasingly used and allows early detection of fetal anomalies [2]. Apart from foetal and maternal indications for termination, obstetric and exogenous indications are increasingly found [3]. This medical termination of pregnancy considerably reduces the number of obstetrical complications that can lead to maternal death and the number of births of children with a disease or malformation that is incompatible with life.

Nearly ten years after the start of maternity activities, this study is conducted to:

$>$ determine the frequency of medical termination of pregnancy;

describe the indications for medical termination of pregnancy;

describe the different techniques used in medical termination of pregnancy.

\section{Methodology}

This was a retrospective and descriptive study conducted at the Principal Clinic of the Togolese Association of Family Well-Being Planning Center (ATBEF) covering the period from May 1st, 2012 to April 30th, 2021, i.e. a period of 9 years.

All patients who underwent a medical termination of pregnancy during the study period and whose term of pregnancy was $<28$ weeks of amenorrhea were included in this study. Information was collected on a survey form from the pa- 
tients' clinical records, admission and hospitalisation registers, referral forms and operative report registers.

Data were entered and analysed using Excel, World and epi-info 7.2.2.

The main variables studied were hospital frequency, diagnostic facilities, main indications, means of evacuation and maternal prognosis. For the study, the following were considered:

- Medical termination of pregnancy (MTP): any termination of pregnancy for medical reasons before 28 weeks of amenorrhoea on the basis of the date of the last menstrual period or on the basis of the ultrasound of the first trimester of pregnancy.

- Fetal termination when the cause was of fetal origin.

- Maternal termination when the cause was related to the mother's health condition.

- Medical termination of pregnancy for obstetrical reasons when the cause was related to an obstetrical complication.

In the case of a situation requiring a Medical termination of pregnancy, the case was presented to the staff of all three gynaecologist-obstetricians, including the head of department and the seven midwives, before the decision was made. Once the decision was made, a discussion was held with the couple to obtain their consent. This consent was most often verbal and the length of this consent varied from patient to patient, especially when the clinical picture did not present an emergency situation. After having obtained the couple's consent, the medical termination of pregnancy was carried out following the steps of the protocol in the department:

The first step consisted in carrying out a basic check-up such as a blood count, uremia, creatininemia, glycemia, prothrombin rate and activated partial thromboplastin time.

The second step was preparation for uterine evacuation. An emergency caesarean section was performed if the clinical picture did not allow evacuation by medical means.

When the clinical picture allowed it, medicated evacuation was performed: either with misoprostol alone or the combination of mifepristone and misoprostol. Three protocols were used in the center. The choice of protocol depended on the woman's clinical condition, the term of the pregnancy, the parity and condition of the cervix, and the history of surgery on the uterus.

When the term of the pregnancy was less than 24 weeks of amenorrhoea, the protocol was used:

- Mifepristone and misoprostol protocol

This protocol consisted of $200 \mathrm{mg}$ of Mifepristone administered orally followed 36 hours later by $400 \mu \mathrm{g}$ of Misoprostol administered sub lingually. If after 3 - 6 hours there was no contraction or expulsion, a further $400 \mu \mathrm{g}$ of misoprostol could be given every 6 hours up to a maximum of five doses.

- Sublingual Misoprostol Protocol

This protocol consists of giving $400 \mu \mathrm{g}$ of Misoprostol sub lingually. If after 3 - 
6 hours there is no contraction or expulsion, another $400 \mu \mathrm{g}$ of misoprostol can be given every 6 hours up to a maximum of five doses.

When the term of pregnancy is greater than 24 weeks of amenorrhoea, only misoprostol was used according to the Intravaginal Misoprostol Protocol

- Intravaginal Misoprostol Protocol

This protocol consists of using misoprostol at 25 to $50 \mu \mathrm{g}$ in the posterior vaginal pouch every 6 hours up to a maximum of five doses.

Regardless of the protocol used, to decrease the duration of labour, an active attitude of amniotomy is recommended as soon as the membranes are accessible, regardless of the term and presentation, and even if the cervix is still long and posterior.

An emergency caesarean section was performed if the clinical picture did not allow evacuation by medical means. The Pfannenstiel technique was used. The type of anaesthesia was determined by the patient's haemodynamic status. As the lower segment was not formed in the 2nd trimester, the caesarean section was low transverse corporal.

- Psychological support

Women who had to undergo a medical termination of pregnancy were given psychological support by the psychologist, midwives and obstetricians before and after the operation.

\section{Results}

\subsection{Frequency}

During the study period, 25 cases of Medical termination of pregnancy were registered. During the same period 4867 deliveries were performed. This corresponds to a hospital frequency of $0.5 \%$.

\subsection{Indication of Medical Terminations of Pregnancy}

\subsubsection{Category of Indications for Termination and Circumstances of Diagnosis}

Fetal, maternal and obstetric causes were the main indications for medical termination of pregnancy in respectively $28 \%, 20 \%$ and $52 \%$.

Obstetrical ultrasound was performed in $100 \%$ of patients. These scans allowed assessment of fetal vitality, approximate gestational age, and the identification of some fetal malformations (28\%) and abnormalities in the fetal adnexa (48\%). Clinical examination alone was diagnostic in $24 \%$ of indications. In $68 \%$ of cases, the clinical examination and ultrasound were used to establish the indication.

\subsubsection{Fetal Indications}

The fetal indications were all fetal malformations (Table 1).

\subsubsection{Maternal Indications}

Maternal indications were: eclampsia (1 case), severe pre-eclampsia (2 cases), acute lung oedema (1 case) and SS haemoglobinopathy (1 case) (Table 2). 
Table 1. Different cases related to fetal causes.

\begin{tabular}{ccccc}
\hline & $\begin{array}{c}\text { Age in } \\
\text { years }\end{array}$ & parity & $\begin{array}{c}\text { term of pregnancy in } \\
\text { weeks of amenorrhoea }\end{array}$ & indications \\
\hline cas1 & 24 & nulliparous & 22 & anencephaly \\
cas2 & 25 & nulliparous & 23 & anencephaly \\
cas3 & 24 & nulliparous & 26 & anencephaly \\
cas4 & 32 & nulliparous & 20 & dwarfism thanatophore \\
cas5 & 36 & paucipary & 28 & dwarfism thanatophore \\
cas6 & 41 & multiparous & 17 & syndrome polymalformatif \\
cas7 & 34 & pauciparous & 20 & syndrome polymalformatif \\
\hline
\end{tabular}

Table 2. Different cases in relation to maternal cause.

\begin{tabular}{ccccc}
\hline & $\begin{array}{c}\text { Age in } \\
\text { years }\end{array}$ & parity & $\begin{array}{c}\text { term of pregnancy in } \\
\text { weeks of amenorrhoea }\end{array}$ & indications \\
\hline cas1 & 20 & nulliparous & 23 & Acute lungs oedema \\
cas2 & 43 & paucipary & 24 & Eclampsia \\
cas3 & 40 & Multiparous & 25 & severe preeclampsia \\
cas4 & 32 & paucipary & 27 & severe preeclampsia \\
cas5 & 20 & nulliparous & 17 & sickle cell attacks \\
\hline
\end{tabular}

\subsubsection{Obstetrical Indications}

Concerning obstetrical indications, premature rupture of membranes complicated by anamnios was the most frequent in $69.2 \%$ of cases, followed by haemorrhagic central placenta in $23 \%$ (Table 3 ).

\subsection{Techniques for Medical Termination of Pregnancy}

\subsubsection{Patient Preparation}

All patients had given their consent for medical termination of pregnancy. The assessment was carried out for those who opted for medical evacuation, i.e. 88\%. Those who had undergone an emergency caesarean section had not undergone this assessment.

\subsubsection{Caesarean Section}

Caesarean section was performed as an emergency in 3 patients, i.e. $12 \%$ of cases.

The main indications for caesarean section were: low hemorrhagic placenta (2 cases), eclampsia (1 case).

\subsubsection{Medicated Evacuation}

Three protocols were used:

Mifepristone and misoprostol protocol in 6 cases (24\%), sub lingual misoprostol protocol in 7 cases (28\%) and intra vaginal misoprostol protocol in 9 cases (36\%).

Regardless of the protocol the number of misoprostol administrations did not 
exceed three doses.

\subsubsection{Time from Misoprostol to Expulsion}

The average time from first misoprostol administration to expulsion was 25 hours with extremes of 10 and 48 hours. Almost $36 \%$ of the patients had expelled within 10 hours (Table 4).

\subsection{Maternal Prognosis}

Haemorrhagic expulsion was noted in 3 cases (12\%). Post abortal endometritis was noted in 2 cases ( $8 \%$ ). Five patients (20\% of cases) were transfused with two bags of packed red blood cells.

All patients were alive with a percentage of $100 \%$.

Table 3. Different cases in relation to obstetric causes.

\begin{tabular}{ccccc}
\hline & $\begin{array}{c}\text { Age in } \\
\text { year }\end{array}$ & Parity & $\begin{array}{c}\text { term of pregnancy in } \\
\text { weeks of amenorrhoea }\end{array}$ & Indications \\
\hline cas1 & 20 & nulliparous & 23 & Anamnios \\
cas2 & 43 & paucipary & 24 & Anamnios \\
cas3 & 40 & Multiparous & 25 & Anamnios \\
cas4 & 32 & paucipary & 27 & Anamnios \\
cas5 & 20 & nulliparous & 17 & Anamnios \\
cas6 & 32 & paucipary & 16 & Anamnios \\
cas7 & 31 & paucipary & 20 & Anamnios \\
cas8 & 25 & nulliparous & 24 & Anamnios \\
cas9 & 29 & paucipary & 26 & Anamnios \\
cas10 & 34 & nulliparous & 23 & Hemorrhagic central placenta \\
cas11 & 28 & nulliparous & 21 & Hemorrhagic central placenta \\
cas12 & 33 & paucipary & 26 & Hemorrhagic central placenta \\
cas13 & 26 & nulliparous & 18 & Septicaemia \\
\hline & & & & \\
\hline
\end{tabular}

Table 4. Distribution of respondents according to induction/expulsion time.

\begin{tabular}{ccc}
\hline & Number & Percent \\
\hline 10 hours & 8 & 36 \\
14 hours & 02 & 9 \\
16 hours & 02 & 9 \\
18 hours & 04 & 18 \\
24 hours & 02 & 9 \\
45 hours & 01 & 5 \\
48 hours & 03 & 14 \\
Total & 22 & 100
\end{tabular}




\section{Discussion}

\subsection{Incidence}

The hospital frequency of Medical termination of pregnancy was $0.5 \%$ of deliveries. This rate is lower than that found by Mothe in France where its frequency was $2 \%$ [4]. This non-negligible rate can be explained by the ultrasound examinations carried out on pregnant women, since in the study, ultrasound enabled some situations to be found that led to medical termination of pregnancy in $70 \%$ of cases. The authors are unanimous on the importance of ultrasound in diagnosing the causes of medical termination of pregnancy [3] [4].

\subsection{Indications for Medical Termination of Pregnancy}

In this study, fetal indications accounted for $28 \%$ of cases. All these indications were fetal malformations. Mothe in his series found $94.4 \%$ fetal indications [4], Marret reported $84 \%$ in his series [3] and Dommergues found $46 \%$ of cases in his series [5]. All the foetal malformations were lethal. This justifies this medical termination of pregnancy in our context. In some publications, the pregnancy is continued to term by the wish of the couple despite the lethal nature of the fetus [6] [7]. This situation can be explained on the one hand by the importance that the parents attach to the time of life, even if brief, with the living child and the constitution of memorial times and on the other hand by religious and socio-cultural obstacles. The decision taken in our context is justified by the often unfavourable outcomes during the evolution, most often marked by intrauterine fetal death, perpartum fetal death, of newborns who will need palliative care as has been noted in the literature. Although the causes of these malformations are investigated by karyotic and genetic studies in some studies [6] [7] [8] [9], this could not be done in our context because of the technical facilities that do not allow these examinations to be performed.

Maternal indications represented 20\% of cases. Marret found 3\% of cases [3]. These indications were justified because the maternal prognosis was already compromised. Indications for maternal toxoplasmosis and rubella or patients living with HIV+ have almost disappeared with the advent of mono and then dual therapy in HIV+ patients and the practice of prophylactic caesarean sections having reduced in utero transmission [3].

The obstetrical indications, premature rupture of membranes (PMR) at an early stage of pregnancy were relatively important in our study (75\% of cases). Marret found 69.2\% obstetrical indications [3] and Dommergues found 6.5\% [4]. These were always premature ruptures of the membranes before $24 \mathrm{SA}$ with severe oligohydramnios for which the chances of fetal survival were low and the risks of infection were greater.

\subsection{Techniques of Medical Termination of Pregnancy}

In $88 \%$ of cases, patients had expelled vaginally and in $12 \%$ of cases, they had undergone an emergency caesarean section. The technique of uterine evacuation 
depends on the haemodynamic status and the speed of extraction of the product of conception to save the woman. In our study, hemorrhage due to the central placenta and the hemodynamic status imposed this evacuation route in order to save the women. The same attitude was found in the work of Marret where caesarean section was necessary in $0.8 \%$ and Mothe performed it in $2 \%$ of cases [3] [4]. The main indication for caesarean section was the haemorrhagic central overlying placenta. In fact, the haemorrhagic central placenta is an exceptional situation in the case of a medical termination of pregnancy but presents a twofold problem for mothers: that of avoiding a risk of haemorrhage during vaginal delivery and that of avoiding the morbidity of a caesarean section often performed in the second trimester on a non-amplified lower segment.

For marginal forms, prostaglandin-induced hypertension, combined with early artificial rupture of the membranes, generally avoids major bleeding [10]. For overlying placenta previa, this may be an indication for an immediate caesarean section. Prior foeticide, lasting a few days, can sometimes help to avoid this by reducing the utero-placental flow, but the risk of haemorrhage remains high [11]. It is the extent of the genital bleeding that has allowed a caesarean section to be performed for maternal rescue.

Apart from emergency situations, the medicinal route is favoured in the literature [3] [4] [12]. In fact, the WHO recommends the combination of mifepristone and misoprostol in IMG [12]. To reduce the duration of labour, an active attitude of amniotomy is recommended as soon as the membranes are accessible, whatever the term and presentation, and even if the cervix is still long and posterior. This attitude was adopted whatever the protocol used in our study as in some studies [4].

\subsection{Complications}

Haemorrhagic expulsion was noted in 3 cases (12\%). Post abortal endometritis was noted in 2 cases (8\%). These complications are also found in other studies [3] [4].

Externalized haemorrhage occurs during the operation or even in the hours or days that follow, and its importance may require a transfusion as was found in our study. Infections were represented by endometritis which would probably be due to the absence of correct asepsis and incomplete evacuation of the uterus.

\subsection{Limitations of the Study}

The retrospective nature of the study and the centre's technical facilities did not allow the causes of the foetal malformations to be identified. The psychological follow-up, as well as the repercussions and experiences of the patients who had benefited from this treatment could not be assessed because of the retrospective nature of the study.

\section{Conclusion}

Medical termination of pregnancy is a type of abortion that is performed in the 
centre. The indications are fetal, maternal and obstetric. The most commonly used evacuation technique is the medicated route. Despite some differences, our practices remain in line with the literature. This series has allowed us to highlight our singularities, and will allow us to improve the management of our patients, in the prevention of haemorrhage and other complications.

\section{Conflicts of Interest}

The authors declare no conflicts of interest regarding the publication of this paper.

\section{References}

[1] Engelmann, P. (2002) Interruption médicale de grossesse: Évolution législative, témoignage et question. Laennec, 50, 16-26. https://doi.org/10.3917/lae.024.0016

[2] Gilles, B. and Suzy, F.P. (2007) Interruption de grossesse pour cause d'anomalie fœetale au cours du deuxième trimestre. Le Médecin du Québec, 42, 114-109.

[3] Marret, H., Perrotin, F., Descamps, P., Magalhaes, A., Lansac, J. and Body, G. (1999) Interruption médicale $2^{\text {ème }}$ et $3^{\text {ème }}$ trimestre. Journal de gynécologie obstétrique et biologie de la reproduction, 28, 245.

[4] Mothe, C. (2016) Interruption médicale de grossesse: Indication et analyse des pratiques obstétricales sur trois ans au CHU de bordeau. Mémoire en Médecine, 145 p. https://dumas.ccsd.cnrs.fr/dumas-01381868

[5] Dommergues, M., Mandelbrot, L., Mahieu-Caputo, D., Boudjema, N. and Durand-Zaleski, I. (2010) Termination of Pregnancy Following Prenatal Diagnosis in France: How Severe Are the Foetal Anomalies? Prenatal Diagnosis, 30, 531-539. https://doi.org/10.1002/pd.2510

[6] Bourdens, M., Tadonnet, J., Hostalery, L., Renesme, L. and Tosello, B. (2017) Severe Fetal Abnormality and Outcomes of Continued Pregnancies: A French Multicenter Retrospective Study. Maternal and Child Health Journal, 21, 1901-1910. https://doi.org/10.1007/s10995-017-2305-0

[7] Kouamé, N., N’goan-Domoua, A.-M., N’gbesso, R.-D. and Kéita, A.-K. (2011) Diagnostic Anténatal d'un cas de Nanisme Thanatophore Type I. Imagerie de la Femme, 21, 171-175. https://doi.org/10.1016/j.femme.2011.09.001

[8] Vaknin, Z., Lahat, Y., Barel, O., Ben-Ami, I., Reish, O., Herman, A. and Maymon, R. (2009) Termination of Pregnancy due to Fetal Abnormalities Performed after 23 Weeks' Gestation: Analysis of Indications in 144 Cases from a Single Medical Center. Fetal Diagnosis and Therapy, 25, 291-296. https://doi.org/10.1159/000229501

[9] Guillem, P., Fabre, B., Cans, C., Robert-Gnansia, E. and Jouk, P.S. (2003) Trends in Elective Terminations of Pregnancy between 1989 and 2000 in a French County (the Isère). Prenatal Diagnosis, 23, 877-883. https://doi.org/10.1002/pd.711

[10] Benachi, A. and Dumez, Y. (2010) Interruption médicale de grossesse. In: Conduites pratiques en médecine foetale, Elsevier, 291-295.

http://linkinghub.elsevier.com/retrieve/pii/B9782294706264000205

https://doi.org/10.1016/B978-2-294-70626-4.00020-5

[11] Borrás, A., Gómez, O., Sanz, M., Martínez, J.M. and Puerto, B. (2010) Feticide Followed by Mifepristone-Misoprostol Regimen for Midtrimester Termination of Pregnancy in Two Cases of Complete Placenta Previa. Fetal Diagnosis and Therapy, 
28, 114-116. https://doi.org/10.1159/000314038

[12] World Health Organization. (2018) Medical Management of Abortion. Geneva, Licence: CC BY-NC-SA 3.0 IGO. 


\section{Annex: Survey Sheet}

1. SOCIO-DEMOGRAPHIC CHARACTERISTICS

- Age (years):

- Occupation:

- Level of education:

- Marital status:

- Place of origin:

\section{BACKGROUND INFORMATION}

Personal history

- Medical (illnesses):

- Obstetrical: Gestity: Parity: A history of abortion:

- Surgical: Caesarean section Yes $\square \mathrm{No} \square$

- If yes, specify: Date Number of times......

- Specific Family History:

3. INDICATION/CAUSAL PATHOLOGY:

Maternal indication:

- terminal stage maternal cancer $\square$

- Cardiac disease $\square$

- Eclampsia

- Preclampsia $\square$

- HELlP Syndrome $\square$

- Other $\square$ If other, specify:

Fetal indication:

- Fetal malformations $\square$ if malformation, specify:

- Chromosomalロ

- Genetica

- Other $\square$ If other, specify:

Obstetrical indication:

- low inserted hemorrhagic placenta $\square$

- rupture of membranes $\square$

- anamnios/oligoamnios $\square$

- Chorioamniotitis $\square$

- other $\square$ if other, specify:

Diagnosis methods:

- ultrasound $\square$

- clinical examination: $\square$

- clinical examination and ultrasound $\square$

- Specify gestational age

4. INTERVENTION

Medication evacuation: Yes $\square$ No $\square$

If yes specify protocol used

Specify time in hours from 1st dose of misoprostol to expulsion:

Caesarean section: yes $\square$ no $\square$ 
Specify indication for caesarean section

Incidents:

Pathology workup: Yes $\square$ No $\square$

\section{COMPLICATIONS:}

- None $\square$

- Delivery haemorrhage $\square$

- Placental retentions $\square$

- Endometritis $\square$

- Uterine rupture $\square$

- other $\square$ if other, specify:.

6. PROGNOSIS

\section{Maternal morbidity:}

- Anemia $\square$

- Blood transfusion: Yes $\square$ No $\square$ If yes, specify the number of packed red blood cells:

- Infections $\square$

- Hysterectomy $\square$

- other $\square$ if other, specify:....

Maternal Mortality:

- Deceased $\square$

- Alive $\square$ 